\title{
In reply: Management of blood pressure alters cerebral oxygen saturation values in the beach chair position
}

\author{
Ingrid Meex, PhD · Cathy De Deyne, MD, PhD · Frank Jans, MD, PhD
}

Received: 1 August 2016/Accepted: 10 August 2016/Published online: 17 August 2016

(C) Canadian Anesthesiologists' Society 2016

\section{To the Editor,}

We want to thank Dr. Kinoshita for comments on our paper. ${ }^{1}$

The lowest acceptable blood pressure during surgery is a subject of discussion and significant controversy. A mean arterial pressure of $50-150 \mathrm{mmHg}$ is often suggested as the range of cerebral autoregulation and therefore a guarantee of adequate cerebral perfusion. There is enormous interindividual variability in the lower-limit autoregulation threshold, however, which makes it difficult to apply any one lower-limit value to a broad population. The average lower limit is probably higher than $50 \mathrm{mmHg}$ (perhaps 60$90 \mathrm{mmHg}$ ) in awake, normotensive patients. $^{2}$ In hypertensive patients, the lower limit of autoregulation might be shifted to the right. ${ }^{3}$

The impact of extracranial contamination on cerebral oxygenation values indeed depends on the technology employed. However, changes in jugular venous bulb oxygenation $^{4}$ and middle cerebral artery blood velocity ${ }^{5}$ were reported in patients in the upright position, suggesting a large intracranial contribution to the measured value.

This manuscript is part of the Limburg Clinical Research Program (LCRP) UHasselt-ZOL-Jessa, supported by the foundation Limburg Sterk Merk, Hasselt University, Ziekenhuis Oost-Limburg and Jessa Hospital.

I. Meex, PhD $(\varangle)$ · C. De Deyne, MD, PhD - F. Jans, MD, PhD Faculty of Medicine and Life Sciences, Hasselt University, Hasselt, Belgium

e-mail: ingrid_meex@hotmail.com

I. Meex, $\mathrm{PhD}$ - C. De Deyne, MD, PhD - F. Jans, MD, PhD Department of Anesthesiology, Intensive Care and Emergency Medicine and Pain Therapy, Ziekenhuis Oost-Limburg, Genk, Belgium
The goal of our study, however, was to compare the data of healthy volunteers with the results of patients. We believe this comparison is of more clinical significance than setting reference values that will always be susceptible to technical issues, independent of the device used.

\section{Conflicts of interest None declared.}

Editorial responsibility This submission was handled by Dr. Philip M. Jones, Associate Editor, Canadian Journal of Anesthesia.

\section{References}

1. Kinoshita H. Management of blood pressure alters cerebral oxygen saturation values in the beach chair position. Can J Anesth 2016; 63: this issue. DOI: 10.1007/s12630-016-0724-9.

2. Drummond JC. The lower limit of autoregulation: time to revise our thinking? Anesthesiology 1997; 86: 1431-3.

3. Murphy GS, Szokol JW. Blood pressure management during beach chair position shoulder surgery: what do we know? Can J Anesth 2011; 58: 977-82.

4. Jeong H, Jeong S, Lim HJ, Lee J, Yoo KY. Cerebral oxygen saturation measured by near-infrared spectroscopy and jugular venous bulb oxygen saturation during arthroscopic shoulder surgery in beach chair position under sevoflurane-nitrous oxide or propofol-remifentanil anesthesia. Anesthesiology 2012; 116: 1047-56.

5. McCulloch TJ, Liyanagama K, Petchell J. Relative hypotension in the beach-chair position: effects on middle cerebral artery blood velocity. Anaesth Intensive Care 2010; 38: 486-91. 